\title{
5 Research Square

\section{Uncertainty Health Risk Assessment and Regional Control of Drinking Water: A Case Study of Hanyuan County, Southwest Mountainous Area, China}

\section{Zhengjiang Lin}

Southwest Jiaotong University

Ying Liu ( $D$ 642823770@qq.com )

Southwest Jiaotong University https://orcid.org/0000-0001-5973-3303

\section{Zhihui Cheng}

Southwest Jiaotong University

Rui Zhao

Southwest Jiaotong University

Han Zhang

Southwest Jiaotong University

\section{Research Article}

Keywords: Drinking water, Uncertain health risk assessment, Monte Carlo simulation, Sequential indicator simulation.

Posted Date: January 18th, 2022

DOI: https://doi.org/10.21203/rs.3.rs-1165475/v1

License: (9) (1) This work is licensed under a Creative Commons Attribution 4.0 International License.

Read Full License 


\title{
Uncertainty Health Risk Assessment and Regional Control of Drinking Water: A Case Study of Hanyuan County, Southwest Mountainous Area, China
}

\author{
Zhengjiang Lin ${ }^{1}$, Ying Liu ${ }^{1} *$, Zhihui Cheng ${ }^{1}$, Rui Zhao ${ }^{1}$ and Han Zhang ${ }^{1}$ \\ 1 Faculty of Geosciences and Environmental Engineering, Southwest Jiaotong University, Chengdu \\ 611756, China; \\ * Correspondence: 642823770@qq.com; Tel.: +86-1388-053-1060
}

Abstract. To evaluate the health risks of drinking water in Hanyuan County, 96 samples of peripheral drinking water were collected from 30 sites in the area. The samples were then analysed for physicochemical properties including $\mathrm{Fe}, \mathrm{Mn}, \mathrm{NH}_{3}-\mathrm{N}, \mathrm{NO}_{3}^{-}, \mathrm{F}-, \mathrm{Pb}, \mathrm{Hg}, \mathrm{As}, \mathrm{Cr}^{6+}, \mathrm{Cd}$, and so on. The health risks of ten trace elements in drinking water were probabilistically assessed using the health risk assessment model and Monte Carlo simulation. On this basis, sequential indicator simulations were used to classify the health risk levels of drinking water in the region, to conduct hierarchical management and control. The results showed that except for $\mathrm{NO}_{3}^{-}$, all other indicators met World Health Organisation standards and China's drinking water sanitation standards. Drinking water presents a specific carcinogenic risk to adults, and the cumulative contribution of $\mathrm{As}$ and $\mathrm{Cr}^{6+}$ exceeds $95 \%$, and has a specific non-carcinogenic risk to children if the cumulative contribution of $\mathrm{F}^{-}, \mathrm{NO}_{3}^{-}$, and As exceeds $90 \%$. Grade I, II, and III non-carcinogenic risk areas accounted for $0.89 \%, 24.72 \%$, and $74.39 \%$ of the total area of Hanyuan County, respectively, while grade I, II, and III carcinogenic risk areas accounted for $27.71 \%, 45.56 \%$, and $26.73 \%$ of the total Hanyuan County area, respectively. Finally, according to the health risk characteristics of each control area, corresponding zoning control suggestions were proposed.

Keyword: Drinking water; Uncertain health risk assessment; Monte Carlo simulation; Sequential indicator simulation

\section{ACKNOWLEDGEMENTS}

This study was supported by the National Natural Science Foundation of China (Grant N o. 51779211, Grant No. 51209178) and the Sichuan Science and Technology Program (Grant No. 2019YJ0233). We sincerely appreciate the editors' and anonymous reviewers' significant comments and suggestions for adding to the quality of the study. 

Case Study of Hanyuan County, Southwest Mountainous Area, China

\section{INTRODUCTION}

Safe drinking water is essential to public health, yet a report jointly issued by the United Nations and the World Health Organisation in 2019 shows that as of 2017, billions of people still lack access to safe drinking water (WHO, 2019). From the water source to the user, drinking water is affected by issues such as water source pollution, outdated water treatment technology, and pipeline network pollution (GUAN et al., 2018). The current focus on drinking water quality is mainly limited to whether it meets, or exceeds, the standard. However, long-term inhalation of, or indirect exposure to, low-dose carcinogens and non-carcinogens in water can also cause significant health risks. (Adimalla, 2020a; Zheng et al., 2017)

Water quality health risk assessments can quantitatively describe the health hazards of various indicators in the water to the human body. Radfard et al. investigated the concentration of pollutants in drinking water in Iran's Sistan and Baluchistan provinces and conducted a health risk assessment of As presence (Radfard et al., 2019). Hadi Rezaei et al. conducted a non-carcinogenic risk assessment of fluoride, nitrate, and nitrite in drinking water in Sanandaj, Iran (Rezaei et al., 2019). Lu et al. conducted carcinogenic and non-carcinogenic risk assessments on 13 trace elements (Co, Mn, Ni, Cu, $\mathrm{Zn}, \mathrm{Se}, \mathrm{Mo}, \mathrm{Cr}, \mathrm{As}, \mathrm{Cd}, \mathrm{Sb}, \mathrm{Hg}$, and $\mathrm{Pb}$ ) in drinking water in Shenzhen, China (Lu et al., 2015). However, due to the number of samples, measurement methods, and differences in individual exposure parameters, the entire process of health risk evaluation is ambiguous, and uncertain analysis methods are sometimes introduced into the assessment. To address the complex drinking water risk analysis problems Lindhe et al. introduced Fault Tree Analysis and a Monte Carlo simulation to effectively evaluate the probability of various water supply system incidents and residents' health risks (Lindhe et al., 2009). Wang et al. used fuzzy interval numbers to evaluate uncertainty with fewer data conditions, which better reflected the influence of exposure parameters such as pollutant concentration, average daily drinking water, and body weight (Wang et al., 2020). Zuzolo et al. used a Monte Carlo simulation and sensitivity analysis to fully assess the influence of pollutant concentration, average daily drinking water, exposure frequency, exposure time, and body weight, as well as obtaining the probabilistic health risk results of As in drinking water in Italy. In addition, they evaluated the parameters that have a more significant impact on health (Zuzolo et al., 2020). Probabilistic evaluation based on a Monte Carlo simulation puts ambiguous parameters in a probability distribution into the risk equation. It then calculates a health risk probability density curve, which reduces the variability caused by changes in pollutant concentration and individual residents' living characteristics in the evaluation process (Saha and Rahman, 2020). Compared to fuzzy interval numbers, the probability density curve can better identify the characteristics of undefined parameters. However, none of the above studies considered the spatial influence of a limited number of sampling sites.

Based on Monte Carlo simulation to describe the influence of exposure parameters, Sequential Indicator Simulation (SIS) was used to assign limited water quality sample data to spatial heterogeneity, through non-parametric stochastic simulation without a hypothetical distribution. It achieved the probabilistic evaluation of drinking water health risks in the Hanyuan area, and the classification of health risk control areas. At the same time, a graded 
regional health risk management strategy was proposed.

\section{Materials and Method}

\subsection{Study area}

Hanyuan County belongs to Ya'an City, Sichuan Province, located on the western edge of the Sichuan Basin (Figure 1). It has good mineralisation conditions and rich mineral resources within the territory; the mining of which may increase the concentration of toxic trace elements in regional water bodies.

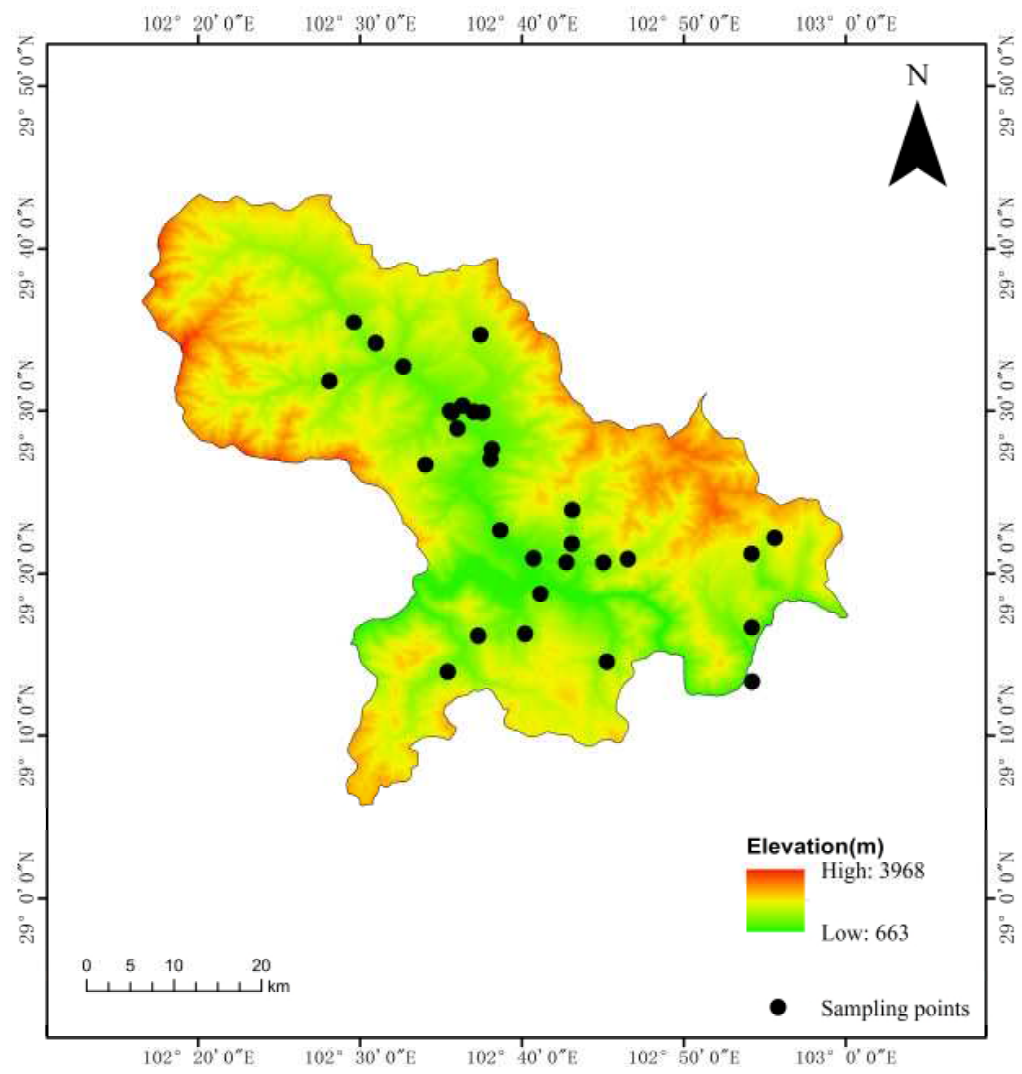

Figure 1. The sampling location of peripheral drinking water and the location of the research area

\subsection{Data sources}

The study collected 96 peripheral drinking water samples from 30 sites in Hanyuan County from 2012 to 2016, with 27 monitoring indicators. We used $\mathrm{Fe}, \mathrm{Mn}, \mathrm{NH}_{3}-\mathrm{N}, \mathrm{NO}_{3}^{-}, \mathrm{F}^{-}, \mathrm{Pb}, \mathrm{Hg}$, $\mathrm{As}, \mathrm{Cr}^{6+}$, and $\mathrm{Cd}$ as the evaluation factors for health risk analysis.

\subsection{Uncertainty analysis and human health risk assessment procedure}

Based on the health risk assessment model recommended by USEPA, the study introduces Monte Carlo simulation and SIS to construct a new uncertainty health risk assessment model. the structure of which is shown in Figure 2. 


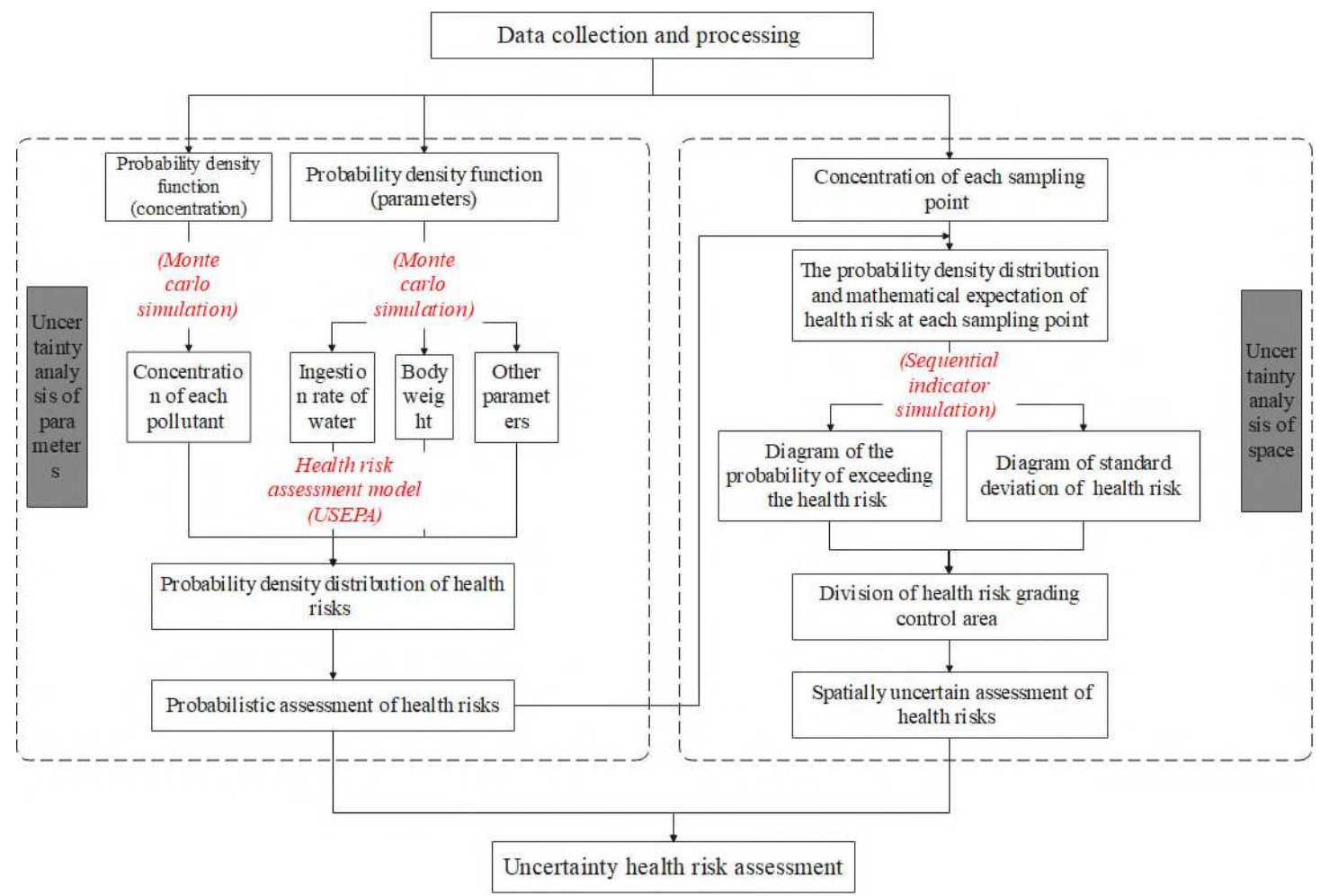

Figure 2. Uncertainty health risk assessment steps

\subsubsection{Probabilistic assessment of health risks}

Toxic trace elements in drinking water enter the human body mainly through inhalation and skin contact, bringing about carcinogenic and non-carcinogenic risks. Existing research shows that the health risks caused by water ingestion are far more significant than those caused by skin contact (Adimalla, 2020b; Chai et al., 2021; Gao et al., 2020). Therefore, this study only considers the threats to health produced by ingesting water. Combining the health risk assessment model proposed by USEPA and actual data from Hanyuan County, the study revised some health risk exposure parameters (Table 1).

Table 1. Distribution of probabilistic health risk evaluation parameters

\begin{tabular}{|c|c|c|c|c|}
\hline Parameters & Symbol & Units & $\begin{array}{c}\text { Probabilistic } \\
\text { Distribution types }\end{array}$ & Values \\
\hline Ingestion rate of water (Adult) & IR(A) & L/day & Triangular distribution & $1.95(0.5 \sim 3.66)^{\mathrm{a}, \mathrm{c}}$ \\
\hline Ingestion rate of water (Children) & $\operatorname{IR}(\mathbf{C})$ & L/day & Triangular & $1.25(0.3 \sim 3)^{\mathrm{a}}$ \\
\hline Body weight (Adult) & BW(A) & $\mathrm{kg}$ & Normal & $59.5 \pm 9.2^{\mathrm{a}}$ \\
\hline Body weight (Children) & $\mathbf{B W}(\mathbf{C})$ & $\mathrm{kg}$ & Triangular & $30(10,70)^{a}$ \\
\hline Exposure frequency & EF & day/year & Constant & $365^{\mathrm{b}}$ \\
\hline Exposure duration (Adult) & $\mathbf{E D}(\mathbf{A})$ & year & Constant & $30^{\mathrm{b}}$ \\
\hline Exposure duration (Children) & $\operatorname{ED}(\mathbf{C})$ & year & Constant & $9^{b}$ \\
\hline $\begin{array}{c}\text { Averaging time (Non-carcinogen. } \\
\text { Adult) }\end{array}$ & $\mathbf{A T}(\mathbf{n c}, \mathbf{A})$ & day & Constant & $\mathrm{ED}(\mathrm{A}) \times 365$ \\
\hline $\begin{array}{c}\text { Averaging time (Non-carcinogen. } \\
\text { Children) }\end{array}$ & AT(nc,C) & day & Constant & $\mathrm{ED}(\mathrm{C}) \times 365$ \\
\hline $\begin{array}{c}\text { Averaging time (Carcinogen) } \\
\text { Gastrointestinal absorption coefficient }\end{array}$ & $\begin{array}{c}\text { AT(c) } \\
\text { ABS }\end{array}$ & day & $\begin{array}{l}\text { Constant } \\
\text { Constant }\end{array}$ & $71.2 \times 365^{\mathrm{c}}$ \\
\hline Carcinogenic slope factor (Ingestion) & SF & $(\mathrm{mg} /(\mathrm{kg} \cdot \text { day }))^{-1}$ & Constant & See Table 2 \\
\hline Reference dose (Ingestion) & Rfd & $\mathrm{mg} /(\mathrm{kg} \cdot$ day $)$ & Constant & \\
\hline
\end{tabular}

${ }^{\mathrm{a}}\left(\right.$ DENG, 2013); ${ }^{\mathrm{b}(U S E P A, ~ 1996) ; ~}{ }^{\mathrm{b}}$ (Xiao-di, 2013);

According to the International Cancer Institute research on the carcinogenicity of substances, $\mathrm{As}, \mathrm{Cr}^{6+}, \mathrm{Cd}$, and their compounds are chemical substances with proven evidence 
of human carcinogenicity, and thus were selected for the carcinogenic risk assessment. Fe, Mn, $\mathrm{NH}_{3}-\mathrm{N}, \mathrm{NO}_{3}^{-}, \mathrm{F}^{-}, \mathrm{Pb}, \mathrm{Hg}, \mathrm{As}, \mathrm{Cr}^{6+}$, and $\mathrm{Cd}$ were selected for the non-carcinogenic risk assessment. The gastrointestinal absorption factors, reference doses of non-carcinogens, and Carcinogen intensity coefficients are shown in Table 3. The study considered the impact of toxic trace elements on adults and children, and the risk assessment model is shown in formulae 1-5 (USEPA, 1996).

$$
\begin{aligned}
& \mathrm{ADD}_{\text {ingestion }}=\frac{\mathrm{C} \times \mathrm{IR} \times \mathrm{EF} \times \mathrm{ED} \times \mathrm{ABS}}{\mathrm{BW} \times \mathrm{AT}}(1) \\
& \mathrm{HQ}_{\text {ingestion }}=\frac{\mathrm{ADD}_{\text {ingestion }}}{\operatorname{Rfd}_{\text {ingetion }}}(2) \\
& \mathrm{CR}_{\text {ingestion }}=\mathrm{ADD}_{\text {ingestion }} \times \mathrm{SF}(3) \\
& \mathrm{HI}=\sum \mathrm{HQ} \text { (4) } \\
& \mathrm{TCR}=\sum \mathrm{CR} \text { (5) }
\end{aligned}
$$

where ADDi is the exposure dose of chemical $\mathrm{i}$; $\mathrm{Ci}$ is the concentration of chemical $\mathrm{i}, \mathrm{mg} / \mathrm{L}$; IR is the daily water intake, $\mathrm{L} / \mathrm{d} ; \mathrm{EF}$ is the exposure frequency, $\mathrm{d} / \mathrm{a}$; $\mathrm{ED}$ is the exposure duration, a; BW is body weight, $\mathrm{kg}$; AT is the average time, day; ABS is the gastrointestinal absorption factor; HQ is the hazard quotient of the drinking water route; Rfd is the reference dose of noncarcinogen for drinking water, $\mathrm{mg} /(\mathrm{kg} \cdot$ day $)$; $\mathrm{CR}$ is the carcinogenic risk of the chemical; $\mathrm{SF}$ is the carcinogenic slope factor, $(\mathrm{mg} /(\mathrm{kg} \cdot \mathrm{day}))^{-1}$; HI is the sum of the harm quotients of multiple pollutants in drinking water; TCR is the total risk of carcinogens in drinking water for multiple pollutants, $(\mathrm{mg} /(\mathrm{kg} \cdot \text { day }))^{-1}$; See Table 2 for specific parameter values.

Table 2. Evaluation index toxicity parameters and physicochemical parameters

\begin{tabular}{cccc}
\hline Trace elements & ABS & Rfd $_{\text {Ingestion }}$ & SF $_{\text {Ingestion }}$ \\
\hline $\mathbf{F e}$ & $0.15^{\mathrm{a}}$ & $0.3^{\mathrm{a}}$ & \\
$\mathbf{M n}$ & $0.04^{\mathrm{a}}$ & $0.046^{\mathrm{a}}$ & \\
$\mathbf{N H 3}-\mathbf{N}$ & $0.2^{\mathrm{c}}$ & $0.97^{\mathrm{c}}$ & \\
$\mathbf{N O}^{-}$ & $0.5^{\mathrm{a}}$ & $1.6^{\mathrm{a}}$ & \\
$\mathbf{F}-$ & $1^{\mathrm{b}}$ & $0.06^{\mathrm{a}}$ & \\
$\mathbf{P b}$ & $1^{\mathrm{b}}$ & $0.0014^{\mathrm{a}}$ & \\
$\mathbf{H g}$ & $0.07^{\mathrm{a}}$ & $0.0003^{\mathrm{a}}$ & $15^{\mathrm{a}}$ \\
$\mathbf{A s}$ & $0.41^{\mathrm{a}}$ & $0.0003^{\mathrm{a}}$ & $41^{\mathrm{a}}$ \\
$\mathbf{C r}$ & $0.02^{\mathrm{a}}$ & $0.003^{\mathrm{a}}$ & $6.1^{\mathrm{a}}$ \\
$\mathbf{C d}$ & $0.05^{\mathrm{a}}$ & $0.0005^{\mathrm{a}}$ & \\
\hline
\end{tabular}

a(USEPA, 2010); (There is no relevant data at present. use ' 1 ' instead); (PRPTV, 2021)(Laboratory)

\subsubsection{Spatial uncertainty analysis of health risks}

The study regards the expected HI and TCR values at the sampling points as variables that change with space, uses SIS to simulate their spatial distribution, and obtains the noncarcinogenic health risk and carcinogenic risk exceedance probability map and standard deviation map. The specific algorithm steps are as follows (Goovaerts, 2001).

(1) $0-1$ discrete coding

The expected values of $\mathrm{HI}$ and TCR of 30 sampling points are converted into indicator values $\mathrm{I}(\mathrm{x}, \mathrm{z})$. 


$$
\mathrm{I}(\mathrm{x}, \mathrm{z})=\left\{\begin{array}{cc}
1, & \mathrm{x} \leq \mathrm{z} \\
0, & \mathrm{x}>\mathrm{z}
\end{array}\right.
$$

where $\mathrm{z}$ is the desired cut-off value of $\mathrm{x}$ (HI and TCR). Take HI as 1 (USEPA, 2004). For TCR, take the ICRP recommended value $5 \times 10^{-5} \mathrm{a}^{-1}$ (Valentin, 2002). When I (x; z) is 0 , HI or TCR exceeds the standard value. That is, a health risk is identified. When $I(x, z)$ is 1 , the situation is reversed.

(2) Obtain several indicator variograms corresponding to the given cutoff values $\mathrm{Z}_{\mathrm{k}}$ according to Eq. (7):

\section{Results and Discussion}

\subsection{Monitoring data statistics}

Monitoring data showed that all indicators met the standards except for the maximum $\mathrm{NO}_{3}^{-}$concentration which exceeded WHO safe levels and China's drinking water sanitation standards. Heavy metals and $\mathrm{Fe}$ were not detected during most months, and the concentrations in individual months were also low. 
Table 3. Descriptive statistics of water quality indicators included in the health risk assessment

\begin{tabular}{ccccccc}
\hline $\begin{array}{c}\text { Trace } \\
\text { elements } \\
(\mathbf{m g} / \mathbf{L})\end{array}$ & $\begin{array}{c}\text { Detection } \\
\text { limit }\end{array}$ & Mean & Min. & Max. & $\begin{array}{c}\text { Standard value } \\
(\text { WHO })\end{array}$ & $\begin{array}{c}\text { Standard value } \\
\text { (China) }\end{array}$ \\
\hline $\mathbf{F e}$ & 0.05 & 0.025 & 0.025 & 0.025 & 0.3 & 0.3 \\
$\mathbf{M n}$ & 0.05 & 0.025 & 0.025 & 0.025 & 0.4 & 0.1 \\
$\mathbf{N H} 3-\mathbf{N}$ & 0.02 & 0.01 & 0.01 & 0.01 & - & 0.5 \\
$\mathbf{N O} \mathbf{O}^{-}$ & 0.15 & 2.76 & 0.075 & 28.26 & 11 & 20 \\
$\mathbf{F -}$ & 0.1 & 0.22 & 0.03 & 0.835 & 1.5 & 1 \\
$\mathbf{P b}$ & 0.0025 & 0.00125 & 0.00125 & 0.00125 & 0.01 & 0.01 \\
$\mathbf{H g}$ & 0.0001 & 0.00005 & 0.00005 & 0.00005 & 0.006 & 0.001 \\
$\mathbf{A s}$ & 0.0001 & 0.000421 & 0.00005 & 0.006 & 0.01 & 0.01 \\
$\mathbf{C r}{ }^{6+}$ & 0.004 & 0.002 & 0.002 & 0.002 & 0.05 & 0.05 \\
$\mathbf{C d}$ & 0.0005 & 0.00025 & 0.00025 & 0.00025 & 0.003 & 0.005 \\
\hline - (there is no standard value). & & & & &
\end{tabular}

\subsection{Probabilistic health risk assessment}

\subsubsection{Non-carcinogenic and carcinogenic risks}

When conducting probabilistic health risk evaluation, the maximum result value may be higher than the actual value, therefore the $95 \%$ quantile of the probabilistic evaluation result is determined as the maximum estimated value of the health risk evaluation result (Kavcar et al., 2009).

The results of the non-carcinogenic risk assessment show that the maximum estimates of the total hazard index for adults and children are 0.89 and 1.41 , respectively, and the probability of exceeding safety level 1 is $2.58 \%$ and $14.58 \%$, respectively (Figure 3). The contribution of each index to the total hazard index is $\mathrm{F}^{-}>\mathrm{NO}_{3}^{-}>\mathrm{As}>\mathrm{Pb}>\mathrm{Cd}>\mathrm{Mn}>\mathrm{Cr}^{6+}>\mathrm{Fe}>\mathrm{Hg}>\mathrm{NH}_{3}-\mathrm{N}$ (Figure 5). The non-carcinogenic risk assessment results show that children have a specific noncarcinogenic risk. Among them, F-, $\mathrm{NO}_{3}^{-}$, and As represent 45.14\%, 25.05\%, and 22.33\%, respectively.

The results of the carcinogenic risk assessment show that, the probability of the total carcinogenic risk of adults and children exceeding $5 \times 10^{-5} \mathrm{a}^{-1}$ are $93.84 \%$ and $4.12 \%$, respectively, and the maximum estimated TCR values are $5.24 \times 10^{-4}, \mathrm{a}^{-1} 4.82 \times 10^{-5} \mathrm{a}^{-1}$ (Figure 4). The contribution of each index to the total carcinogenic risk is $\mathrm{As}>\mathrm{Cr}^{6+}>\mathrm{Cd}$ (Figure 5). According to the carcinogenic risk assessment results, adults have a greater risk of carcinogenesis, among which $\mathrm{As}$ and $\mathrm{Cr}^{6+}$ contribute significantly at $88.52 \%$ and $10.97 \%$, respectively. 


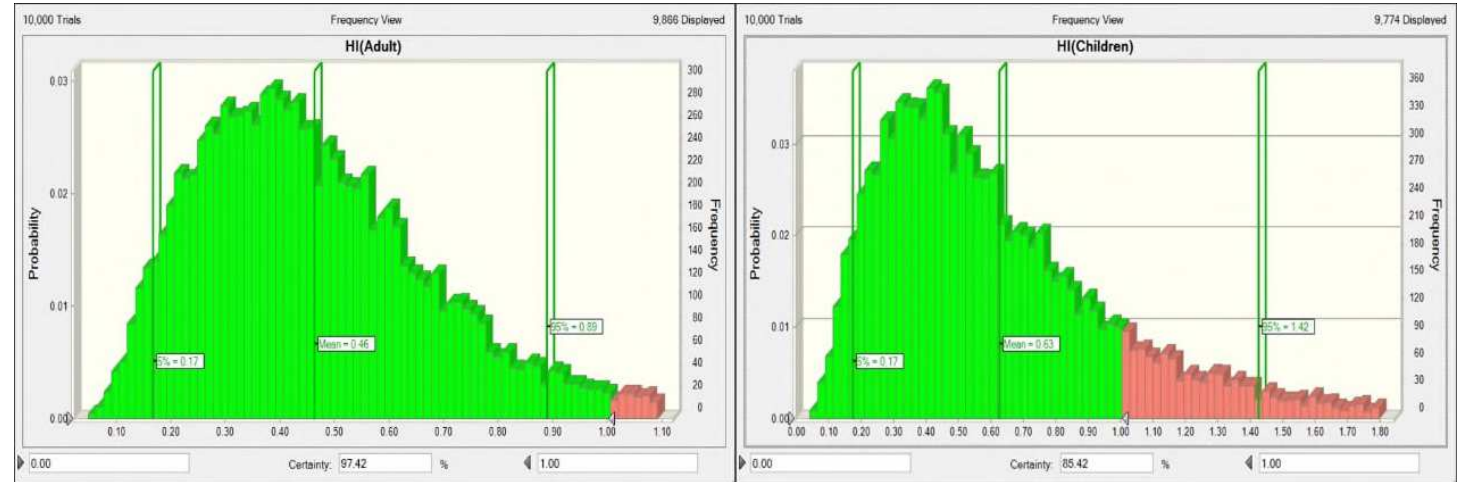

Figure 3. Probabilistic assessment results of non-carcinogenic risk

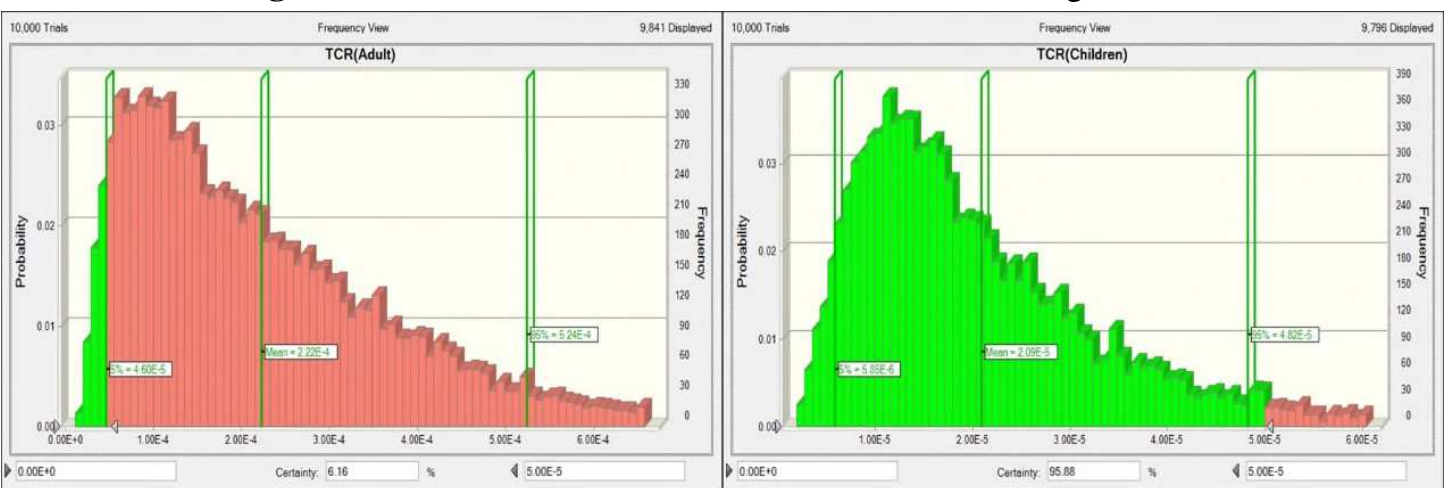

Figure 4. Probabilistic assessment results of carcinogenic risk
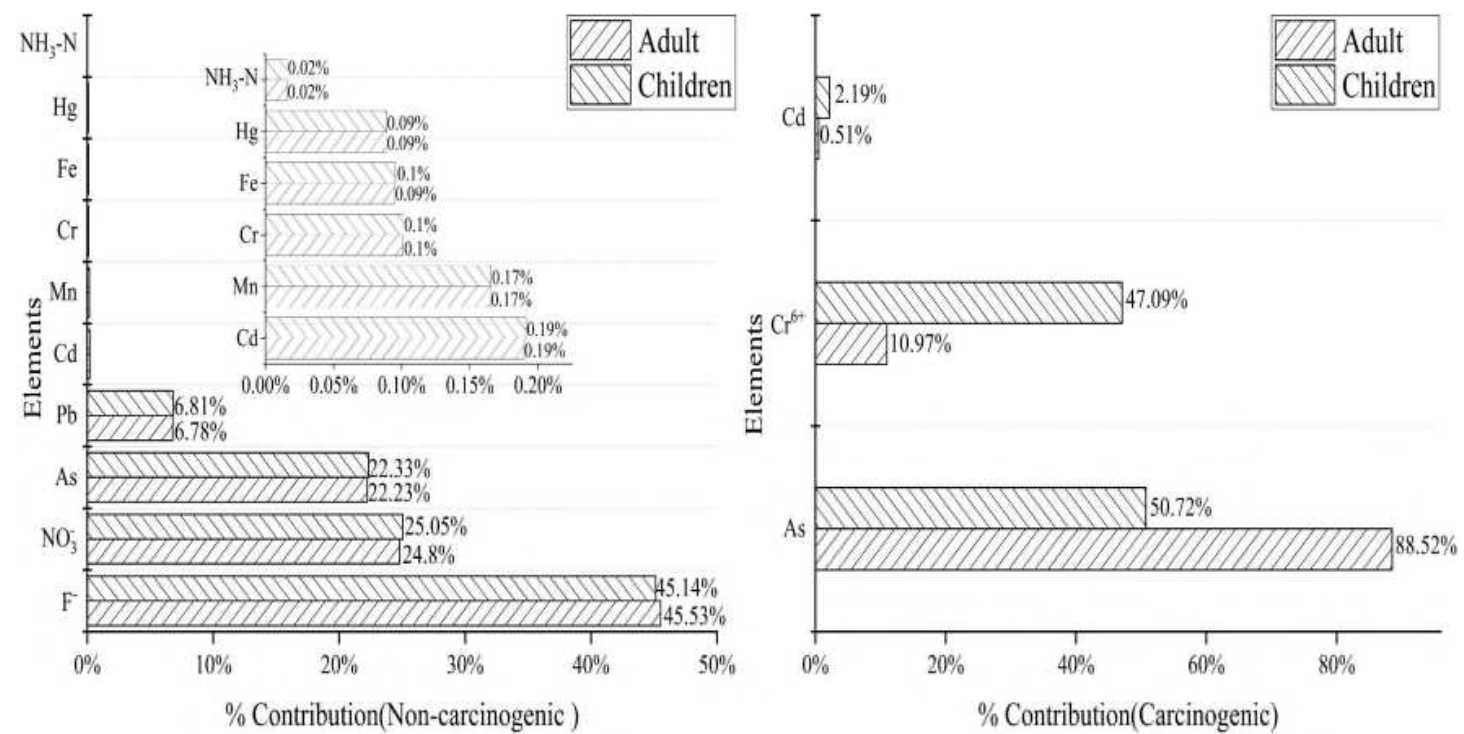

Figure 5. Non-carcinogenic risk and carcinogenic risk contribution rate of each trace element

\subsubsection{Sensitivity analysis}

Sensitivity analysis results reflect the relationship between each evaluation parameter variable and health risk. The absolute value of the sensitivity reflects the correlation between the evaluation parameter variable and the health risk, and the positive or negative sensitivity indicates whether the evaluation parameter variable is positively or negatively correlated with that health risk.

The results of non-carcinogenic risk sensitivity analysis are shown in Figure 6. IR has the most significant impact on the non-carcinogenic risk of adults and children, 
with correlation coefficients of $48.8 \%$ and $40.6 \%$, respectively. In addition, as far as adults are concerned, changes in $\mathrm{F}^{-}, \mathrm{As}$, and $\mathrm{NO}_{3}^{-}$concentration have a more significant impact on non-carcinogenic risk than body weight. This conclusion is contrary to the results of the sensitivity analysis of children. That is, changes in $\mathrm{F}^{-}, \mathrm{As}$, and $\mathrm{NO}_{3}^{-}$ concentration will increase the likelihood of non-carcinogenic risks in adults.

The carcinogenic risk sensitivity analysis results are shown in Figure 7. The concentration of arsenic has the most significant impact on the carcinogenic risk of adults, and IR has the most significant effect on the carcinogenic risk of children, with correlation coefficients of $74.1 \%$ and $40.8 \%$, respectively. Bodyweight is also a significant factor in cancer risk in both adults and children.

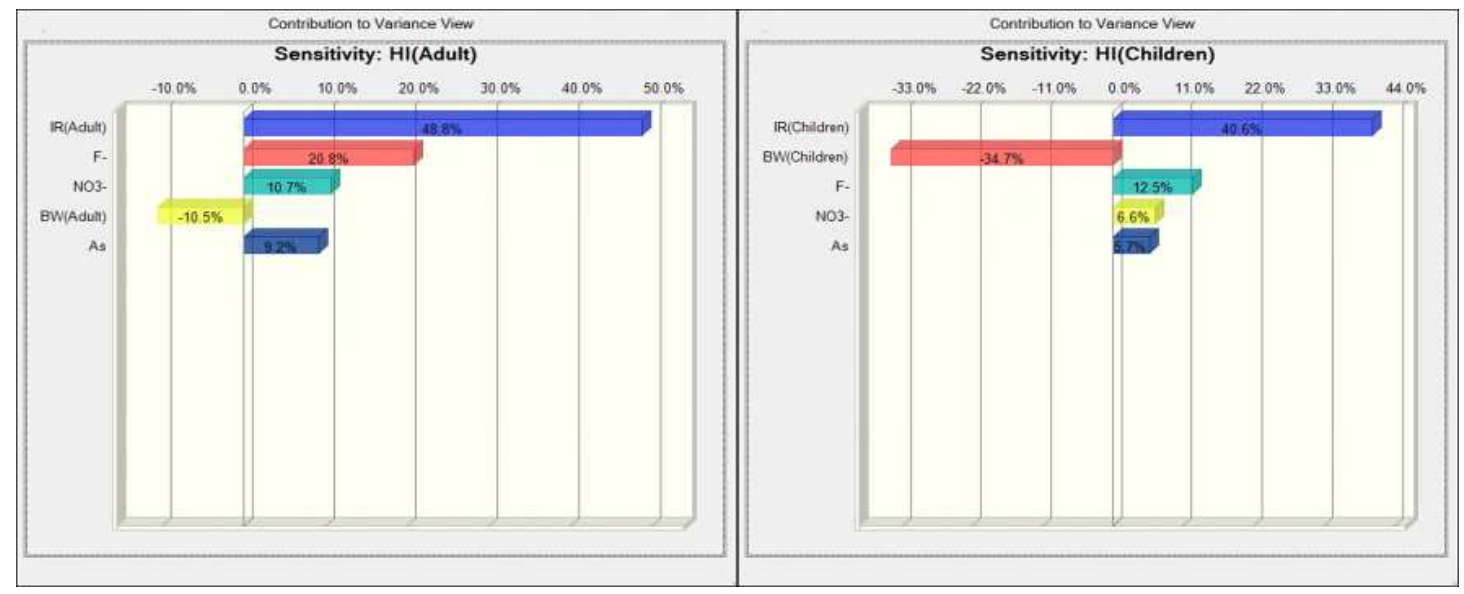

Figure 6. Non-carcinogenic risk sensitivity analysis

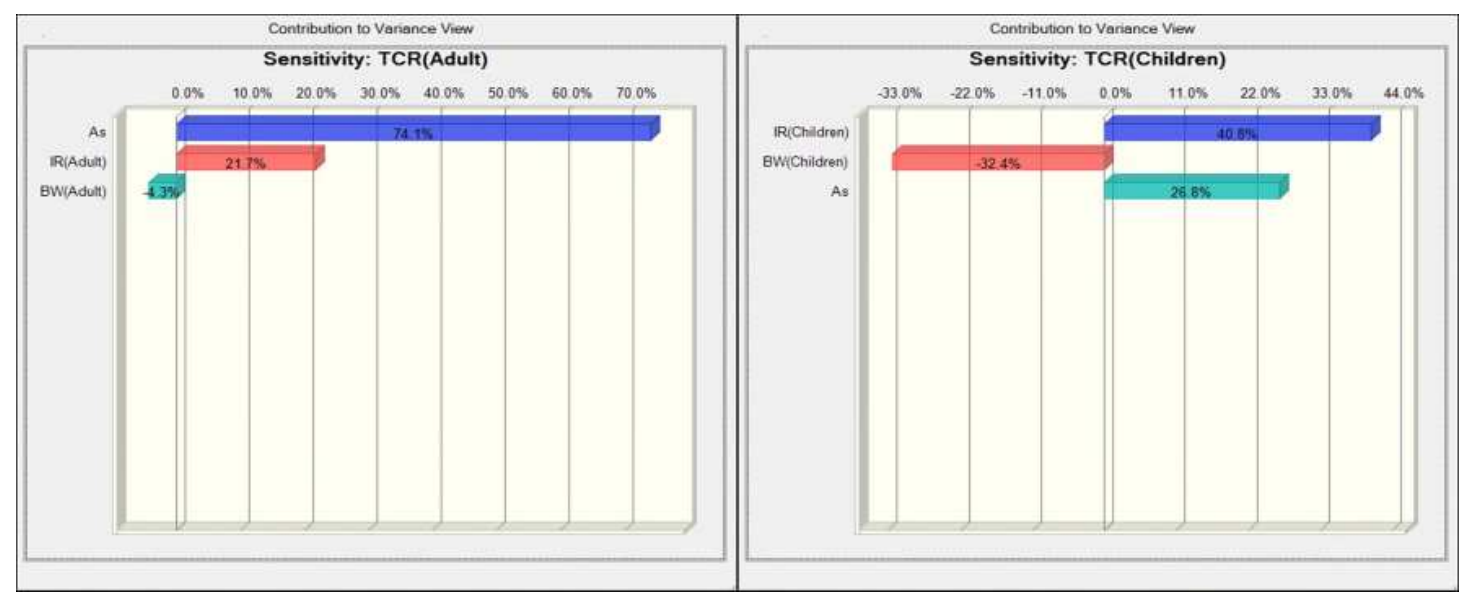

Figure 7. Sensitivity analysis of carcinogenic risk

\subsection{Spatial uncertainty health risk analysis}

\subsubsection{Semivariogram of indicator variables}

In the SIS, ' 1 ' and ' $5 \mathrm{e}-5$ ' were selected as the indicator variable thresholds for $\mathrm{HI}$ and TCR, respectively. In this research, we used a particle swarm optimisation algorithm and least-squares method to fit three theoretical variation models (spherical, exponential, and Gaussian) of indicator variables including adult HI, adult TCR, child HI, and child TCR. The theoretical semivariogram with the least error was selected as the experimental semivariogram, and the 
parameter values are shown in Table 4.

Table 4. Fitting error of semivariogram and model parameters

\begin{tabular}{|c|c|c|c|c|c|}
\hline \multirow{2}{*}{ Simulation index } & \multirow{2}{*}{ Model type } & \multirow{2}{*}{ RMSE } & \multicolumn{3}{|c|}{ Model parameters } \\
\hline & & & $\mathbf{C}_{0}$ & $\mathrm{C}+\mathrm{C}_{0}$ & Range (m) \\
\hline \multirow{3}{*}{ Adult HI, } & Spherical & 0.0188 & \multirow{3}{*}{0.023} & \multirow{3}{*}{0.021} & \multirow{3}{*}{35000} \\
\hline & Exponential & 0.0187 & & & \\
\hline & Gaussian & 0.0186 & & & \\
\hline \multirow{3}{*}{ Adult TCR } & Spherical & 0.0271 & \multirow{3}{*}{0.164} & \multirow{3}{*}{0.098} & \multirow{3}{*}{2867} \\
\hline & Exponential & 0.0333 & & & \\
\hline & Gaussian & 0.0331 & & & \\
\hline \multirow{3}{*}{ Child HI } & Spherical & 0.0188 & \multirow{3}{*}{0.023} & \multirow{3}{*}{0.019} & \multirow{3}{*}{33824} \\
\hline & Exponential & 0.0187 & & & \\
\hline & Gaussian & 0.0186 & & & \\
\hline \multirow{3}{*}{ Child TCR } & Spherical & 0.0306 & \multirow{3}{*}{0.202} & \multirow{3}{*}{0.050} & \multirow{3}{*}{2348} \\
\hline & Exponential & 0.0339 & & & \\
\hline & Gaussian & 0.0333 & & & \\
\hline
\end{tabular}

\subsubsection{Probability spatial distribution of health risks}

According to the probabilistic health risk assessment results, the drinking water in Hanyuan County contains various health risks to both adults and children. To study the distribution and uncertainty of the health risks, to both adults and children, of drinking water in this area, SIS was used to conduct random modelling. Taking adult non-carcinogenic risks as an example, the random model generated by the SIS method better describes the spatial distribution of health risks in the study area and reflects its spatial uncertainty (Figure 8 and Figure 9).
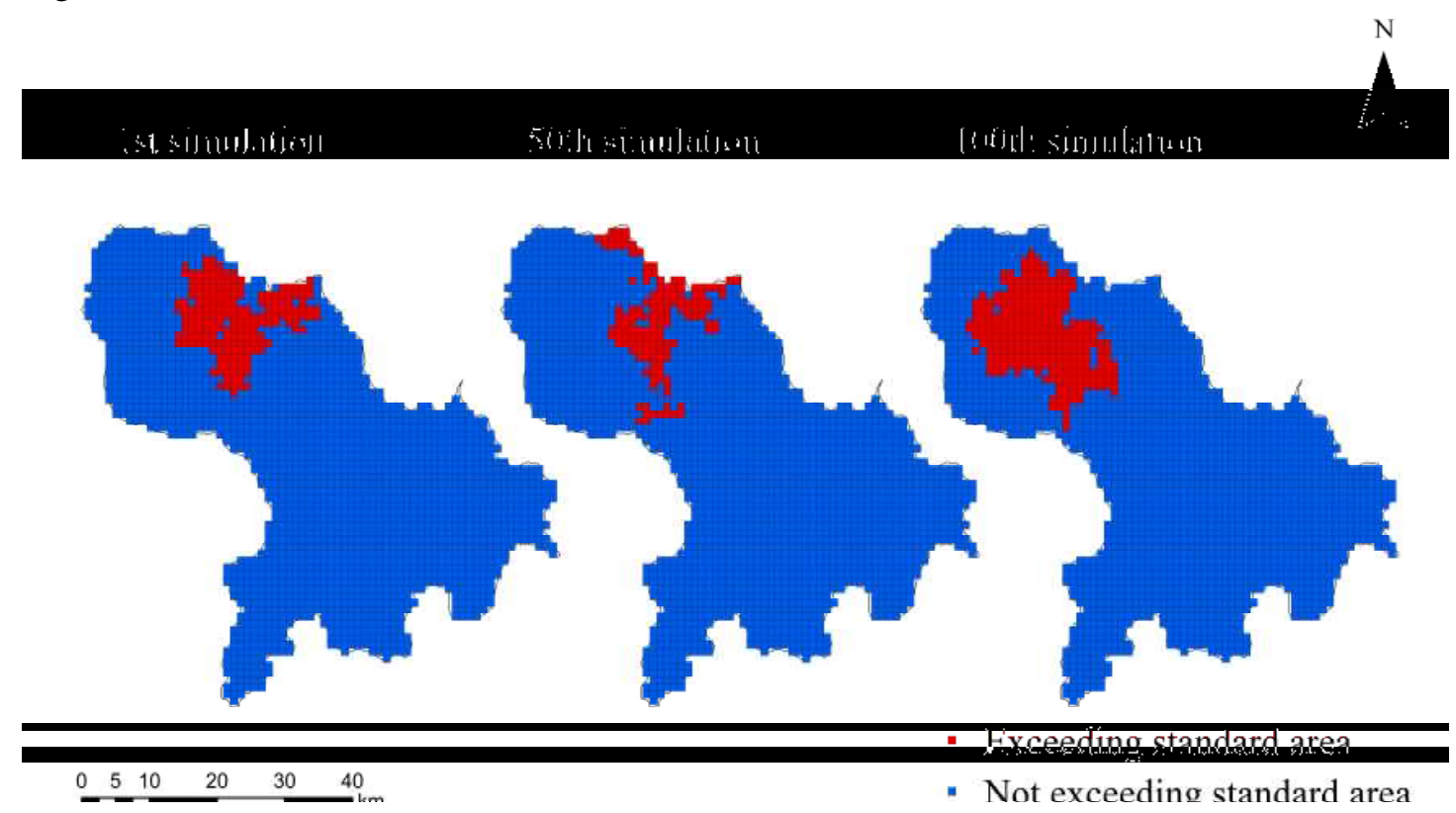

Figure 8. Results of the 1st, 50th, and 100th SIS simulations of non-carcinogenic risk of drinking water to adults in Hanyuan County

After performing 100 SIS on the health risks to adults and children in the study area, we 
used Formulae (8)-(9) to perform statistical analysis to obtain the diagram of the probability of health risk and the digram of variance of health risk (Figure 9, Figure 10). The regional risk probability value and standard deviation respectively represent the possibility and uncertainty of health risks to humans caused by various pollutants in drinking water. When the risk probability value is high, risks to health are more likely in that area. When the risk probability value is low, the health risk is low, but its standard deviation is large, which leads to increased uncertainty. To provide environmental risk managers with extensive, intuitive, and accurate information, we referred to the classification of groundwater and soil health risk assessments and hierarchical risk control areas by Zeng Guangming and Huang Jinhui (Huang et al., 2016; Zeng et al., 2009). This study uses 5\%, 25\%, 50\%, 75\%, and 95\% probability of exceeding the standard as the benchmark, and the health risks of the study area are separated.

As shown in Figure 9, the spatial distribution of non-carcinogenic risks exceeding the probability is the same in adults and children. The area with a standard-exceeding probability value greater than 0.75 is mainly located around the S30 point. The areas where the risk of adult carcinogenesis is more significant than 0.75 are mainly located around S5, S8, S12, S13, S19, and S21. The areas where the risk of children's carcinogenesis is more significant than 0.75 are mainly located around S10, S12, S13, S18, S19, and S21.

It can be seen from Figure 9 and Figure 10 that the areas with a health risk probability significant standard deviation within the study area are mainly concentrated in the locations where the health risk exceeds the standard probability of $25 \%$ to $75 \%$. This signifies significant uncertainty, indicating that the health risk level of the region is unstable, and could possibly change to high risk.

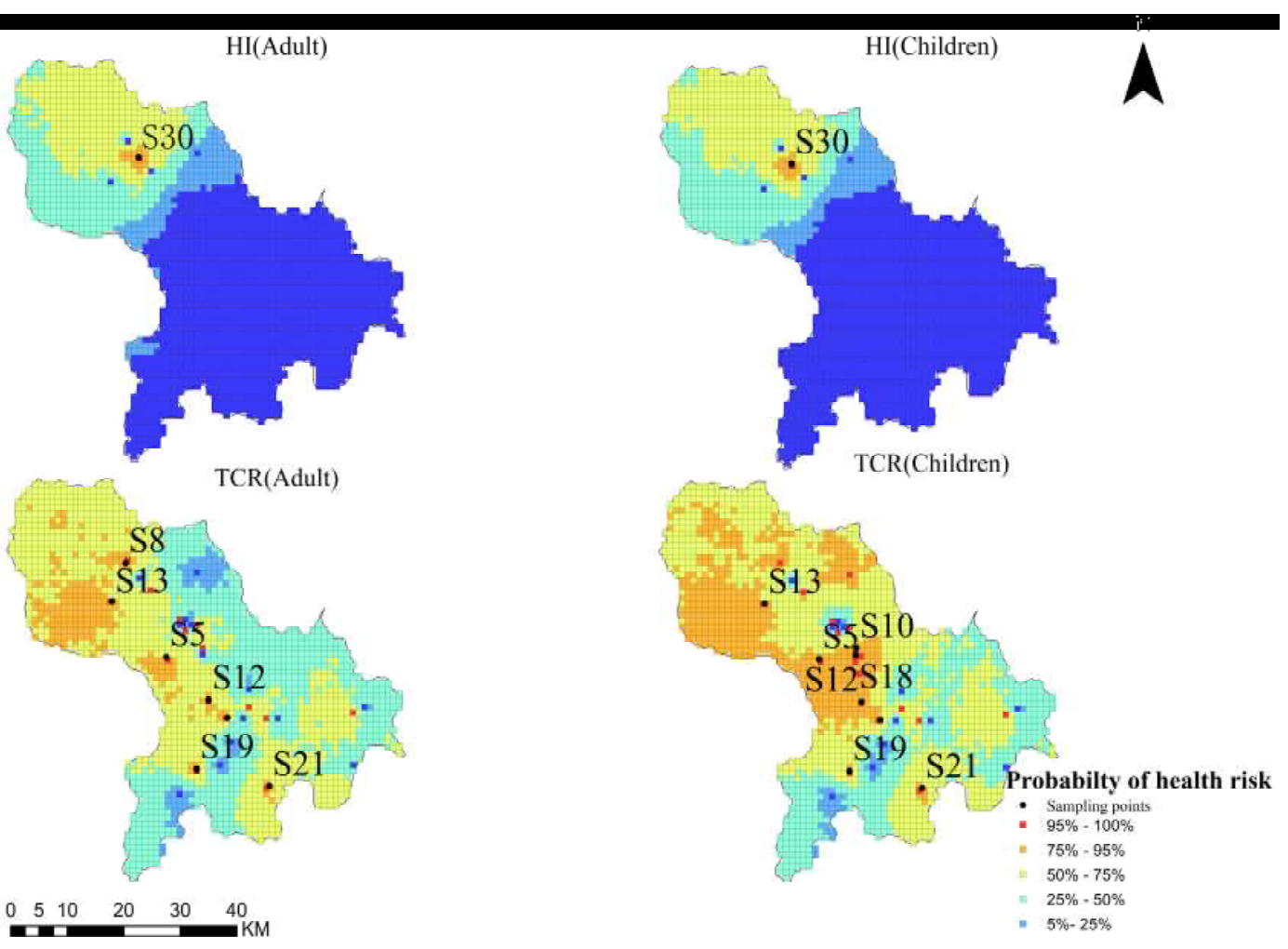

Figure 9. Spatial distribution of health risk probability in Hanyuan County 


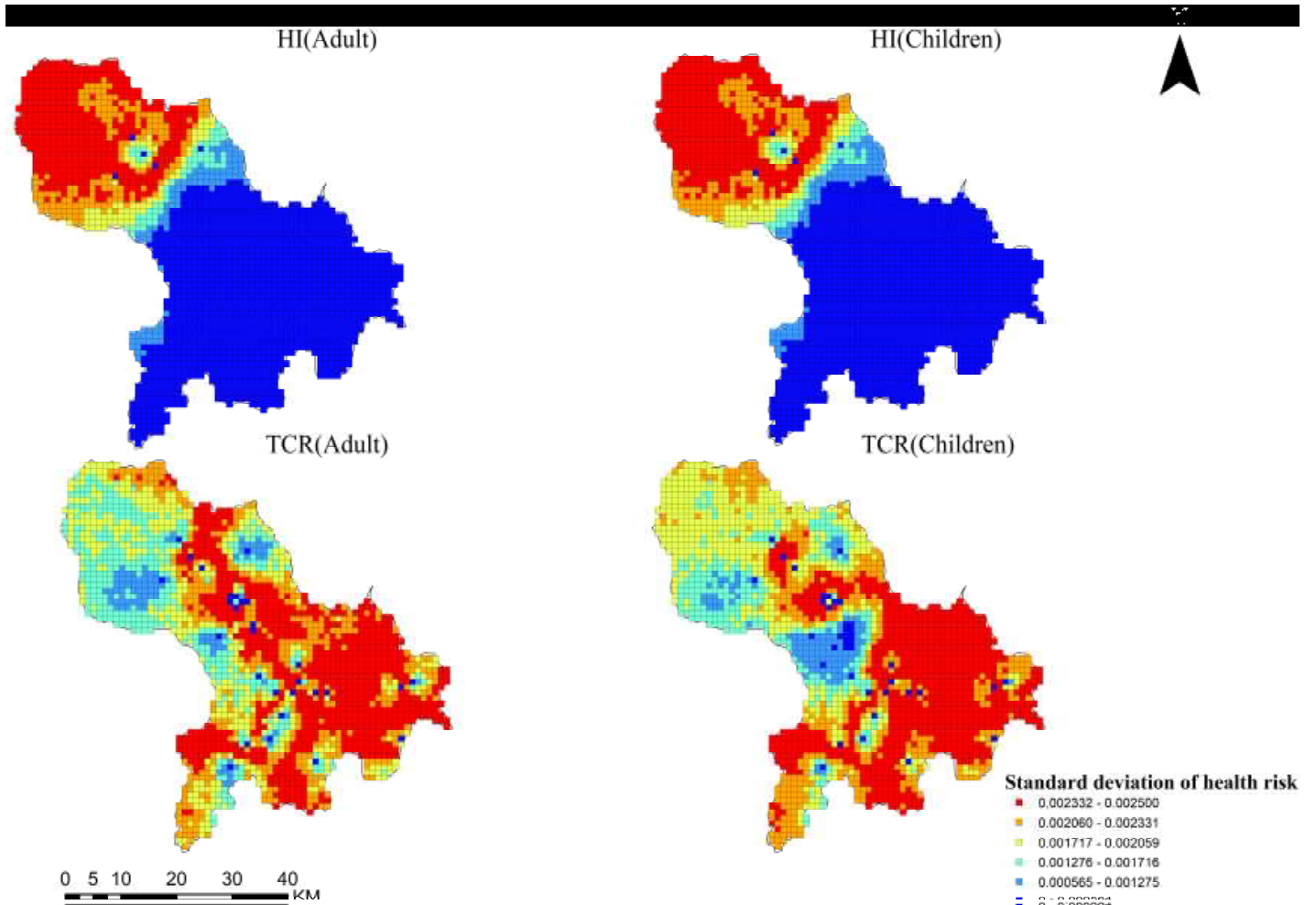

Figure 10. Spatial distribution of health risk standard deviation in Hanyuan County

\subsection{Grading of control areas according to health risk levels}

Combining Figure 9 and Figure 10, the areas with carcinogenic risk and non-carcinogenic with over-standard probability greater than $75 \%$ are classified as Class I areas, and areas with a $25 \%-75 \%$ probability, that is, areas with large standard deviations, are classified as Class II areas. The remaining areas are described as level III areas (Figure 11).

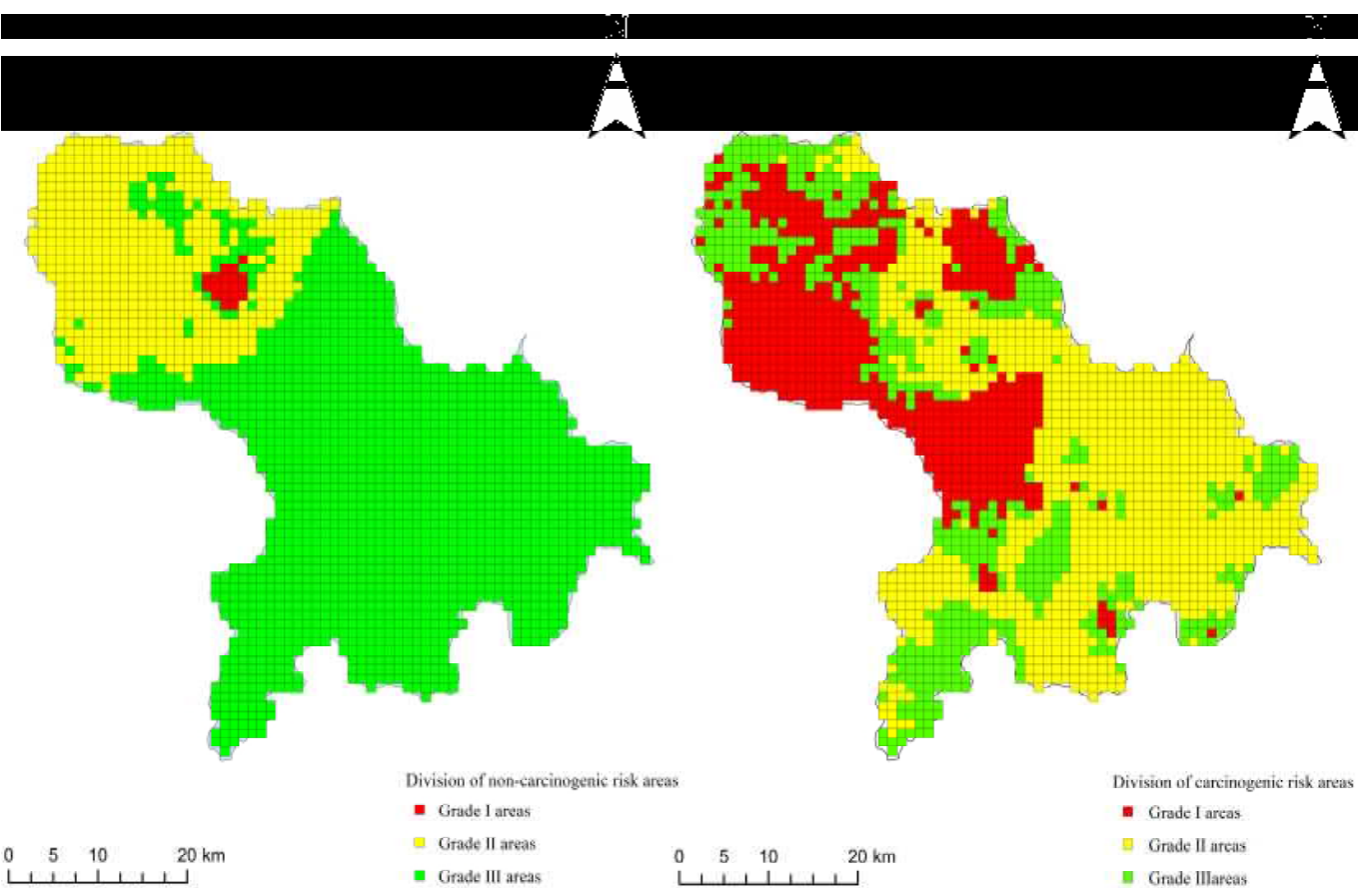

Figure 11. Health Risk Zoning of Drinking Water in Hanyuan County 
The Grade I non-carcinogenic and carcinogenic risk covered $19.67 \mathrm{~km}^{2}$ and $612.58 \mathrm{~km}^{2}$, accounting for $0.89 \%$ and $27.71 \%$ of the total Hanyuan County area, respectively. For drinking water in Grade I areas, due to the high probability of non-carcinogenic and carcinogenic risk exceeding the standard, various pollutants in the drinking water pose a more significant threat to health, thus this area should be regarded as a priority control area for environmental risks. For pollutants containing $\mathrm{F}^{-}, \mathrm{NO}_{3}^{-}$, As, and $\mathrm{Cr}^{6+}$ contributing to health risks, the water processing plants within those study areas need to undertake corresponding purification processes. In addition, all risk information should be made public, to prompt widespread awareness among local residents and encourage them to monitor their drinking water quality.

Grade II non-carcinogenic and carcinogenic risk areas constituted $546.48 \mathrm{~km}^{2}$ and $1007.19 \mathrm{~km}^{2}$, accounting for $24.72 \%$ and $45.56 \%$ of the total Hanyuan County area, respectively. For drinking water in Grade II areas, since the non-carcinogenic risk, and probability of carcinogenic risk exceeding the standard are relatively small, the standard deviation is large, and the drinking water health risk could increase from low to high. Therefore, these areas should be considered as environmental risk key control areas. Relevant departments need to strengthen the monitoring and early warning system of water sources and drinking water quality in highrisk areas within the study area and take measures to reduce pollution when necessary to avoid deterioration of drinking water quality.

Grade II non-carcinogenic and carcinogenic risk areas covered $1644.53 \mathrm{~km}^{2}$ and $590.92 \mathrm{~km}^{2}$, accounting for $24.72 \%$ and $45.56 \%$ of the total area of Hanyuan County, respectively. For drinking water in Grade III areas, since various pollutants in this area constitute low noncarcinogenic and carcinogenic risk to adults and children, the sites should be determined as general environmental risk control areas. It is recommended that relevant departments conduct regular sampling and inspections of the drinking water quality in these areas.

\section{Conclusion}

The study evaluated the hazards to human health posed by $\mathrm{Fe}, \mathrm{Mn}, \mathrm{NH}_{3}-\mathrm{N}, \mathrm{NO}_{3}^{-}, \mathrm{F}^{-}, \mathrm{Pb}$, $\mathrm{Hg}, \mathrm{As}, \mathrm{Cr}^{6+}$, and $\mathrm{Cd}$ in the peripheral drinking water of Hanyuan County, analysed the uncertainty of risk, and classified of health risk control areas. The conclusions are as follows:

(1) Except for $\mathrm{NO}_{3}^{-}$, all other indicators met World Health Organisation standards and China's water sanitation standards.

(2) The maximum estimated value of the children's total hazard index is 1.41 , with a $14.58 \%$ probability of exceeding safety level 1 , and the contribution of $\mathrm{F}-, \mathrm{NO}_{3}^{-}$, and As is relatively large. The maximum estimate of the total carcinogenic risk for adults exceeding $5.24 \times 10^{-4} \mathrm{a}^{-1}$ is $93.84 \%$, and the contribution of As and $\mathrm{Cr}^{6+}$ is relatively significant.

(3) Sensitivity analysis results showed that daily water intake, body weight, $\mathrm{F}-, \mathrm{NO}_{3}^{-}$, and As concentration significantly affect the health risks of both adults and children.

(4) The non-carcinogenic risks of grade I, grade II, and grade III areas account for roughly $0.89 \%, 24.72 \%$, and $74.39 \%$ of the total area of Hanyuan County. The carcinogenic risks of grade I, grade II, and grade III areas accounted for about $27.71 \%, 45.56 \%$, and $26.73 \%$ of the total area of Hanyuan County.

(5) The drinking water quality meets relevant standards, which does not denote that there is no health risk. Combining Monte Carlo simulation uncertainty analysis and 
sequential indicator simulation can effectively determine different risk control areas. In view of the risk characteristics of various regions, suggestions are made to assist relevant departments in formulating more scientific, economic, and flexible drinking water safety management strategies.

\section{FUNDING}

This study was supported by the National Natural Science Foundation of China (Grant N o. 51779211, Grant No. 51209178) and the Sichuan Science and Technology Program (Grant No. 2019YJ0233).

\section{COMPETING INTERESTS}

The authors have no relevant financial or non-financial interests to disclose.

\section{AUTHOR CONTRIBUTIONS}

All authors contributed to the conception and design of the research. Conceptualization: Ying Liu; Methodology:Zhengjiang Lin, Ying Liu, Zhihui Cheng; Formal analysis and investigation: Zhengjiang Lin, Ying Liu, Zhihui Cheng; Writing - original draft preparation: Zhengjiang Lin; Writing - review and editing: Ying Liu, Rui Zhao, Han Zhang; Funding acquisition:Ying Liu; Resources: Ying Liu; Supervision: Ying Liu. The final manuscript read and approved by all authors.

\section{COMPLIANCE WITH ETHICAL STANDARDS}

All authors have read this manuscript and would like to have it considered exclusively for publication in Environmental Science and Pollution Research. None of the material related to this manuscript has been published or is under consideration for publication elsewhere, including the internet. The authors have no relevant financial or non-financial interests to disclose. The Research did not involve human participants and/or animals.

\section{REFERENCES}

Adimalla N. Controlling factors and mechanism of groundwater quality variation in semiarid region of South India: an approach of water quality index (WQI) and health risk assessment (HRA). Environmental Geochemistry and Health 2020a; 42: 1725-1752.

Adimalla N. Spatial distribution, exposure, and potential health risk assessment from nitrate in drinking water from semi-arid region of South India. Human and Ecological Risk Assessment 2020b; 26: 310-334.

Chai NP, Yi X, Xiao J, Liu T, Liu YJ, Deng L, et al. Spatiotemporal variations, sources, water quality and health risk assessment of trace elements in the Fen River. Science of the Total Environment 2021; 757.

DENG Y. Health Risk Assessment Associated with WaterQuality of Rural Drinking Water Sources:A case of Mingshan Distract. Sichuan Agricultural University, 2013.

Gao S, Li CS, Jia C, Zhang HL, Guan Q, Wu XC, et al. Health risk assessment of groundwater nitrate contamination: a case study of a typical karst hydrogeological unit in East China. Environmental Science and Pollution Research 2020; 27: 9274-9287. 
Goovaerts P. Geostatistical modelling of uncertainty in soil science. Geoderma 2001; 103: 3-26.

GUAN Y, KONG H, ZHANG S, LI X, LIU H, LIN Y. PROGRSS IN DRKING WATE R SAFETY FOR RESIDENTS. Environmental Engineering 2018; 36: 18-22.

Huang JH, Liu WC, Zeng GM, Li F, Huang XL, Gu YL, et al. An exploration of spatial human health risk assessment of soil toxic metals under different land uses using sequential indicator simulation. Ecotoxicol Environ Saf 2016; 129: 199-209.

Kavcar P, Sofuoglu A, Sofuoglu SC. A health risk assessment for exposure to trace metals via drinking water ingestion pathway. International Journal of Hygiene and Environmental Health 2009; 212: 216-227.

Laboratory ORN. Provisional Peer Reviewed Toxicity Values (PPRTV). Available at: https://hhpprtv.ornl.gov/.

Lindhe A, Rosen L, Norberg T, Bergstedt O. Fault tree analysis for integrated and probabilistic risk analysis of drinking water systems. Water Research 2009; 43: 1641-1653.

Lu SY, Zhang HM, Sojinu SO, Liu GH, Zhang JQ, Ni HG. Trace elements contamination and human health risk assessment in drinking water from Shenzhen, China. Environmental Monitoring and Assessment 2015; 187.

Radfard M, Yunesian M, Nabizadeh R, Biglari H, Nazmara S, Hadi M, et al. Drinking water quality and arsenic health risk assessment in Sistan and Baluchestan, Southeastern Province, Iran. Human and Ecological Risk Assessment 2019; 25: 949-965.

Rezaei H, Jafari A, Kamarehie B, Fakhri Y, Ghaderpoury A, Karami MA, et al. Health-risk assessment related to the fluoride, nitrate, and nitrite in the drinking water in the Sanandaj, Kurdistan County, Iran. Human and Ecological Risk Assessment 2019; 25: 1242-1250.

Saha N, Rahman MS. Groundwater hydrogeochemistry and probabilistic health risk assessment through exposure to arsenic-contaminated groundwater of Meghna floodplain, central-east Bangladesh. Ecotoxicology and Environmental Safety 2020; 206.

SHI Z, LI Y, CHENG J. Stochastic Simulation of Spatial Distribution and Uncertainty Assessment of Heavy Metal in Paddy Soil. ENVIRONMENTAL SCIENCE 2007: 209-214.

USEPA. Quantitative Uncertainty Analysis of Superfund Residential Risk Pathway Models for Soil and Groundwater:White Paper. 1996.

USEPA. Risk Assessment Guidance for Superfund Volume I: Human Health Evaluation Manual. 2004; Part E, Supplemental Guidance for Dermal Risk Assessment.

USEPA. Integrated Risk Information System (IRIS). Available at: https://www.epa.gov/iris. 2010.

Valentin J. Basic Anatomical and Physiological Data for Use in Radiological Protection: Reference Values. Annals of the Icrp 2002; 32: 1-277.

Wang YM, Zhu GC, Engel B, Wu YF. Probabilistic human health risk assessment of arsenic under uncertainty in drinking water sources in Jiangsu Province, China. Environmental Geochemistry and Health 2020; 42: 2023-2037.

WHO. One third of the world's people do not have access to safe drinking water. Chinese Journal of Health Policy 2019; 12: 58.

Xiao-di L. Exposure Factors Handbook of Chinese Population: Exposure Factors Handbook of Chinese Population, 2013.

Zeng GM, Liang J, Guo SL, Shi L, Xiang L, Li XD, et al. Spatial analysis of human health risk associated with ingesting manganese in Huangxing Town, Middle China. Chemosphere 2009; 77: $368-375$. 
404

405

406

407

408

409

410

Zheng X, Xu J, Wang H, Liu X, Yao D, Lv J. Health risk assessment of a reservoir-type water source in the northeastern region of China. Human and Ecological Risk Assessment: An International Journal 2017; 23.

Zuzolo D, Cicchella D, Demetriades A, Birke M, Albanese S, Dinelli E, et al. Arsenic: Geochemical distribution and age-related health risk in Italy. Environmental Research 2020; 182. 